OPEN ACCESS

Edited by:

Antonio Miceli,

Istituto Clinico Sant'Ambrogio, Italy

Reviewed by:

Bleri Celmeta,

Istituto Clinico Sant'Ambrogio, Italy

Igor Belluschi,

Vita-Salute San Raffaele

University, Italy

${ }^{*}$ Correspondence:

Gabby Elbaz-Greener

Gabby@hadassah.org.il

tThese authors have contributed equally to this work

Specialty section:

This article was submitted to

Heart Surgery

a section of the journal

Frontiers in Cardiovascular Medicine

Received: 07 August 2021

Accepted: 13 September 2021

Published: 08 October 2021

Citation:

Elbaz-Greener G, Rozen G,

Carasso S, Kusniec F, Yarkoni M, Marai I, Strauss B, Wijeysundera HC, Smart FW, Erez E, Alcalai R, Planer D and Amir O (2021) The Relationship Between Body Mass Index and In-Hospital Mortality in Patients Following Coronary Artery Bypass Grafting Surgery. Front. Cardiovasc. Med. 8:754934. doi: 10.3389/fcrm.2021.754934

\section{The Relationship Between Body Mass Index and In-Hospital Mortality in Patients Following Coronary Artery Bypass Grafting Surgery}

\author{
Gabby Elbaz-Greener ${ }^{1,2 \star t}$, Guy Rozen ${ }^{3,4,5 \dagger}$, Shemy Carasso ${ }^{6,7}$, Fabio Kusniec $^{6,7}$, \\ Merav Yarkoni ${ }^{1,2}$, Ibrahim Marai ${ }^{6,7}$, Bradley Strauss $^{8}$, Harindra C. Wijeysundera ${ }^{8}$, \\ Frank W. Smart ${ }^{9}$, Eldad Erez ${ }^{10}$, Ronny Alcalai ${ }^{1,2}$, David Planer ${ }^{1,2}$ and Offer Amir ${ }^{1,2,6,7}$ \\ ${ }^{1}$ Department of Cardiology, Hadassah Medical Center, Jerusalem, Israel, ${ }^{2}$ Faculty of Medicine, Hebrew University of \\ Jerusalem, Jerusalem, Israel, ${ }^{3}$ Cardiology Division, Hillel Yaffe Medical Center, Hadera, Israel, ${ }^{4}$ The Ruth and Bruce \\ Rappaport Faculty of Medicine, Technion, Haifa, Israel, ${ }^{5}$ Cardiology Division, Harvard Medical School, Massachusetts \\ General Hospital, Boston, MA, United States, ${ }^{6}$ Division of Cardiovascular Medicine, Baruch Padeh Medical Center, Poriya, \\ Israel, ${ }^{7}$ The Azrieli Faculty of Medicine in the Galilee, Bar-Ilan University, Safed, Israel, ${ }^{8}$ Division of Cardiology, Schulich Heart \\ Centre, Sunnybrook Health Sciences Centre, University of Toronto, Toronto, ON, Canada, ${ }^{9}$ Louisiana State University School \\ of Medicine, New Orleans, LA, United States, ${ }^{10}$ Department of Cardio Surgery, Hadassah Medical Center, Hebrew University \\ of Jerusalem, Jerusalem, Israel
}

Background: The association between Body Mass Index (BMI) and clinical outcomes following coronary artery bypass grafting (CABG) remains controversial. Our objective was to investigate the real-world relationship between BMI and in-hospital clinical course and mortality, in patients who underwent CABG.

Methods: A sampled cohort of patients who underwent CABG between October 2015 and December 2016 was identified in the National Inpatient Sample (NIS) database. Outcomes of interest included in-hospital mortality, peri-procedural complications and length of stay. Patients were divided into $6 \mathrm{BMl}\left(\mathrm{kg} / \mathrm{m}^{2}\right)$ subgroups; (1) under-weight 19, (2) normal-weight 20-25, (3) over-weight 26-30, (4) obese I 31-35, (5) obese ॥ $36-39$, and (6) extremely obese $\geq 40$. Multivariable logistic regression model was used to identify predictors of in-hospital mortality. Linear regression model was used to identify predictors of length of stay (LOS).

Results: An estimated total of 48,710 hospitalizations for CABG across the U.S. were analyzed. The crude data showed a U-shaped relationship between BMI and study population outcomes with higher mortality and longer LOS in patients with BMl $\leq 19$ $\mathrm{kg} / \mathrm{m}^{2}$ and in patients with BMl $\geq 40 \mathrm{~kg} / \mathrm{m}^{2}$ compared to patients with BMl $20-39 \mathrm{~kg} / \mathrm{m}^{2}$. In the multivariable regression model, BMl subgroups of $\leq 19 \mathrm{~kg} / \mathrm{m}^{2}$ and $\geq 40 \mathrm{~kg} / \mathrm{m}^{2}$ were found to be independent predictors of mortality.

Conclusions: A complex, U-shaped relationship between BMl and mortality was documented, confirming the "obesity paradox" in the real-world setting, in patients hospitalized for CABG.

Keywords: body mass index (BMI), coronary artery bypass grafting surgery (CABG), ischemic heart, outcome, mortality 


\section{INTRODUCTION}

Body mass index (BMI) is widely used for routine characterization of weight status in epidemiological and clinical research, however with some limitations, for instance not distinguishing fat from muscle mass (1). The World Health Organization (WHO) classifies a patient body weight by six categorical subgroups, (1) under-weight, BMI $\leq 18.5 \mathrm{~kg} / \mathrm{m}^{2}$; (2) normal-weight, BMI $18.5-24.9 \mathrm{~kg} / \mathrm{m}^{2}$; (3) over-weight, BMI $25-29.9 \mathrm{~kg} / \mathrm{m}^{2}$; (4) obese class I, BMI $30-34.9 \mathrm{~kg} / \mathrm{m}^{2}$; (5) obese class II, BMI $35-39.9 \mathrm{~kg} / \mathrm{m}^{2}$; and (6) extremely obese BMI $\geq$ $40 \mathrm{Kg} / \mathrm{m}^{2}(1,2)$. In population-based studies, higher BMI was associated with increased incidence of major cardiovascular risk factors $(1,3)$. BMI has been proven an independent risk factor for various cardiovascular conditions such as acute coronary syndrome, congestive heart failure, sudden cardiac death, atrial and ventricular arrhythmia and stroke $(3,4)$.

Several studies investigated the effect of different BMI arrays on short- and long-term mortality rates post cardiac surgery with contradictory conclusions. Some studies suggested that obesity was an independent negative predictor of morbidity and mortality (5-8) while others showed more favorable outcomes after cardiac surgery in obese patients (9-13). This phenomenon has been referred to as the obesity paradox (9-13). One explanation for this paradox is that patients with higher BMI may have a lower postoperative bleeding volume and transfusion rate; thus, such patients may save blood products during on-pump CABG factor that contributes to higher survival rates (14). On the other hand, sternal wound infections are more prevalent in obese patients and prior studies have shown increased morbidity and mortality rates in obese patients (15-17).

In the current study, we aimed to describe the BMI distribution and in-hospital outcomes among different BMI subgroups post-CABG, during the index hospitalization.

\section{METHODS}

\section{Data Source}

The data were drawn from the National Inpatient Sample (NIS), the Healthcare Cost and Utilization Project (HCUP), and Agency for Healthcare Research and Quality (AHRQ) $(18,19)$. The NIS database only includes de-identified data; therefore, this study was considered exempt from institutional review by the Human Research Committee.

The NIS is the largest collection of data on all-payer hospitalizations in the United States (U.S.), and represents an approximate $20 \%$ stratified sample of all inpatient discharges from U.S. hospitals (20). This includes information at the hospital-level, such as hospital region, teaching status, bed size and cost of hospitalization, and other data at the patient-level, including demographic characteristics, primary and secondary diagnoses and procedures, comorbidities and length of stay (LOS). National estimates can be calculated using the patientlevel and hospital-level sampling weights that are provided by the HCUP.

For the purpose of this study, we obtained data for the years 2015 and 2016. The International Classification of Diseases, 10th
Revision, Clinical Modification (ICD-10-CM) was used from the last quarter of 2015 and thereafter for reporting diagnoses and procedures in the NIS database during the study period. For each index hospitalization, the database provides a principal discharge diagnosis and a maximum of 14 or 24 additional diagnoses, in addition to a maximum of 15 procedures. We restricted our cohort to the period during which data was coded with ICD-10 codes, because the ICD-10 system includes individual codes for $\mathrm{BMI}$ values and ranges.

\section{Study Population and Variables}

We identified patients 18 years of age or older with a primary diagnosis of CABG procedure based on ICD-10-CM code starting with I10.PR1 with 0210-0213xxx codes, who have one of the Z68.x codes as I10-Dx1 to I10-Dx30. These codes represent the six subgroups in our study; Z68, Z68.20-25, Z68.26-30, Z68.31-35, Z68.36-39, and Z68.4 (BMI $\leq 19$ under-weight group; BMI 20-25 normal-weight group; BMI 26-30 over-weight group; BMI 31-35 obese I group, BMI 36-39 obese II group and BMI equal or $\geq 40$ extremely obese group, respectively).

The following patient demographics were collected from the database: age, sex, and race. Prior comorbidities were identified by measures from the AHRQ. For the purpose of calculating Deyo-Charlson Comorbidity Index (Deyo-CCI), additional comorbidities were identified from the database using ICD-10-CM codes. Deyo-CCI is a modification of the Charlson Comorbidity Index, containing 17 comorbid conditions of differential weights, with a total score ranging from 0 to 33 (detailed information on Deyo-CCI is provided in the Appendix Table 1). Higher Deyo-CCI scores indicate a greater burden of comorbid diseases and is associated with mortality 1year after admission (21). The index has been used extensively in studies from administrative databases, with proved validity in predicting short- and long-term outcomes $(22,23)$.

Our primary outcome in this study was in-hospital mortality. The secondary outcomes included in-hospital periprocedural complications and length of stay in the hospital. In-hospital complications were defined as previously reported (24-26) and included known cardiac surgery related complications as follows: (1) Pericardial complications as tamponade, hemopericardium, pericarditis and pericardiocentesis; (2) Cardiac complications (during or resulting from procedure), defined as cardiac block, myocardial infarction, cardiac arrest, congestive heart failure, cardiogenic shock and others; (3) Pulmonary complications, defined as pneumothorax/hemothorax, diaphragm paralysis, post-operative respiratory failure, and other iatrogenic respiratory complications; (4) Vascular complications, defined as accidental puncture or laceration during a procedure, injury to blood vessels, arteriovenous fistula, injury to retroperitoneum, vascular complication requiring surgical repair, re-open, and other vascular complications; (5) Infection, defined as fever, septicemia, and post-procedural aspiration pneumonia; (6) Neurological, defined as nervous system complication, unspecified, central nervous system complication, iatrogenic cerebrovascular infarction or hemorrhage cerebrovascular effect, and transient ischemic attack; (7) Acute renal failure; (8) Cardiogenic shock; (9) Diaphragmatic paralysis; (10) Re-open 
TABLE 1 | Frequency distribution of baseline characteristics by BMl group in CABG patients.

\begin{tabular}{|c|c|c|c|c|c|c|c|c|}
\hline BMI groups $\left(\mathrm{Kg} / \mathrm{m}^{2}\right)$ & $\begin{array}{c}\quad \leq 19 \\
\text { Under-weight }\end{array}$ & $\begin{array}{c}20-25 \\
\text { Normal-weight }\end{array}$ & $\begin{array}{c}\text { 26-30 } \\
\text { Over-weight }\end{array}$ & $\begin{array}{c}\text { 31-35 } \\
\text { Obese I group }\end{array}$ & $\begin{array}{c}\text { 36-39 } \\
\text { Obese II group }\end{array}$ & $\begin{array}{l}\qquad \mathbf{4 0} \\
\text { Extremely obese }\end{array}$ & Total & $P$-value \\
\hline Unweighted ${ }^{\mathrm{a}}$ & 137 & 263 & 1,570 & 3,544 & 1,952 & 2,276 & 9,742 & \\
\hline Age group, $\%$, years & & & & & & & & $<0.001$ \\
\hline $18-44$ & 1.5 & 0.8 & 1.8 & 3.0 & 4.8 & 5.2 & 3.6 & \\
\hline$\geq 75$ & 27.7 & 27.8 & 19.0 & 13.5 & 10.0 & 7.6 & 12.9 & \\
\hline Gender, \% & & & & & & & & $<0.001$ \\
\hline Male & 67.2 & 71.1 & 72.9 & 74.6 & 68.6 & 62.5 & 70.1 & \\
\hline Female & 32.8 & 28.9 & 27.1 & 25.3 & 31.3 & 37.5 & 29.9 & \\
\hline Race, \% & & & & & & & & $<0.001$ \\
\hline Hypertension & 48.9 & 58.6 & 66.2 & 67.3 & 67.9 & 65.4 & 66.3 & $<0.001$ \\
\hline Congestive heart failure & 21.9 & 15.2 & 13.9 & 11.8 & 13.8 & 17.2 & 14.1 & $<0.001$ \\
\hline Diabetes mellitus & 16.8 & 34.2 & 36.9 & 41.4 & 44.9 & 50.1 & 42.9 & $<0.001$ \\
\hline Chronic renal disease & 28.5 & 24.7 & 20.8 & 20.3 & 21.8 & 24.3 & 21.9 & $<0.001$ \\
\hline Chronic obstructive pulmonary disease & 47.4 & 23.6 & 22.7 & 21.9 & 24.4 & 27.0 & 24.1 & $<0.001$ \\
\hline Peripheral vascular disease & 30.7 & 20.5 & 17.8 & 14.3 & 13.1 & 12.0 & 14.5 & $<0.001$ \\
\hline Atrial Fibrillation/Flutter & 40.9 & 31.9 & 33.0 & 31.8 & 33.5 & 35.6 & 33.3 & $<0.001$ \\
\hline Prior Ml & 20.4 & 22.1 & 19.3 & 19.7 & 18.9 & 18.9 & 19.3 & 0.085 \\
\hline Deyo-CCI, \% & & & & & & & & $<0.001$ \\
\hline 1 & 9.5 & 18.3 & 20.0 & 19.9 & 20.6 & 17.6 & 19.3 & \\
\hline 2 or higher & 87.6 & 74.5 & 70.3 & 69.2 & 70.7 & 75.8 & 71.6 & \\
\hline
\end{tabular}

MI, Myocardial Infraction; Deyo-CCl, Deyo-Charlson Comorbidity Index.

${ }^{a}$ Represents the number of observations in the NIS database.

${ }^{b}$ Represents total national estimates after applying sampling weights.

surgery; (11) Permanent pacemaker implantation (PPM); (12) New onset atrial fibrillation; (13) Wound infection.

Detailed information on all ICD-10-CM codes used to identify in-hospital complications, is summarized in the Appendix Table 2.

\section{Statistical Analysis}

The chi-square $\left(\chi^{2}\right)$ and Wilcoxon Rank Sum tests were used to compare categorical variables and continuous variables, respectively. The NIS provides discharge sample weights that are calculated within each sampling level as the ratio of discharges in the universe to discharges in the sample (25). We generated a weighted logistic regression model to identify independent predictors of in-hospital mortality. Candidate variables included patient-level characteristics, Deyo-CCI and hospital-level factors. We included all candidate variables that were associated with our primary and secondary outcome in our final multivariable regression model. A linear regression model was used to identify predictors of LOS.

For all analyses, we used $\mathrm{SAS}^{\circledR}$ software version 9.4 (SAS Institute Inc., Cary, NC.) A $p<0.05$ was considered statistically significant.

\section{RESULTS}

\section{Study Cohort}

A total sample of 9,742 CABG hospitalizations across the U.S. during 2015 (last quarter) and 2016 were included in the analysis. After implementing the weighting method, these represented an estimated total of 48,710 hospitalizations for CABG, in patients who had BMI information during the index hospitalization. The majority of patients $(70.1 \%)$ were male, and the mean age of the cohort was $63.4 \pm 22.1$ years. A smaller proportion of CABG patients were underweight with a BMI $\leq 19 \mathrm{~kg} / \mathrm{m}^{2}$ (Table 1).

\section{Patient Characteristics, Presentation of Acute Myocardial Infraction, and Treatment Approach by BMI Group}

Study population baseline and clinical characteristics are presented in detail in Tables 1, 2. Male predominance and higher prevalence of comorbidities such as chronic obstructive pulmonary disease, chronic renal disease, atrial fibrillation/flutter and higher Deyo-CCI scores were observed in both under-weight $\left(\mathrm{BMI} \leq 19 \mathrm{~kg} / \mathrm{m}^{2)}\right.$ and extremely obese groups $\left(\mathrm{BMI} \geq 40 \mathrm{~kg} / \mathrm{m}^{2}\right.$; Table 1). Forty-five percent of the patients underwent coronary 
TABLE 2 | Frequency distribution of clinical course and outcomes by BMl group.

\begin{tabular}{|c|c|c|c|c|c|c|c|c|}
\hline & $\begin{array}{c}\quad \leq 19 \\
\text { Under-weight }\end{array}$ & $\begin{array}{c}20-25 \\
\text { Normal-weight }\end{array}$ & $\begin{array}{c}26-30 \\
\text { Over-weight }\end{array}$ & $\begin{array}{c}\text { 31-35 } \\
\text { Obese I group }\end{array}$ & $\begin{array}{c}\text { 36-39 } \\
\text { Obese II group }\end{array}$ & $\begin{array}{c}\quad \geq 40 \\
\text { Extremely obese }\end{array}$ & Total & $P$-value \\
\hline NSTEMI, \% & 38.7 & 33.5 & 29.4 & 27.9 & 28.1 & 29.7 & 28.9 & $<0.0001$ \\
\hline STEMI, \% & 10.2 & 7.2 & 5.6 & 5.4 & 4.6 & 4.1 & 5.1 & $<0.0001$ \\
\hline $\begin{array}{l}\text { Coronary } \\
\text { angiography, \% }\end{array}$ & 44.5 & 47.5 & 46.9 & 45.5 & 42.0 & 44.4 & 44.8 & $<0.0001$ \\
\hline $\begin{array}{l}\text { Concomitant valve } \\
\text { surgery, \% }\end{array}$ & 3.6 & 3.8 & 2.9 & 2.5 & 3.1 & 3 & 2.9 & 0.005 \\
\hline Mortality, \% & 4.4 & 1.5 & 1.3 & 1.0 & 1.0 & 2.2 & 1.4 & $<0.0001$ \\
\hline $\begin{array}{l}\text { LOS (days), Mean } \pm \\
\text { SEM }\end{array}$ & $14.89 \pm 0.77$ & $10.54 \pm 0.55$ & $9.18 \pm 0.16$ & $8.83 \pm 0.10$ & $9.00 \pm 0.13$ & $10.69 \pm 0.18$ & $9.51 \pm 0.09$ & $<0.0001$ \\
\hline
\end{tabular}

LOS, Length of Stay; NSTEMI, Non-ST Segment Elevation Myocardial Infraction; STEMI, ST segment Myocardial Infraction.

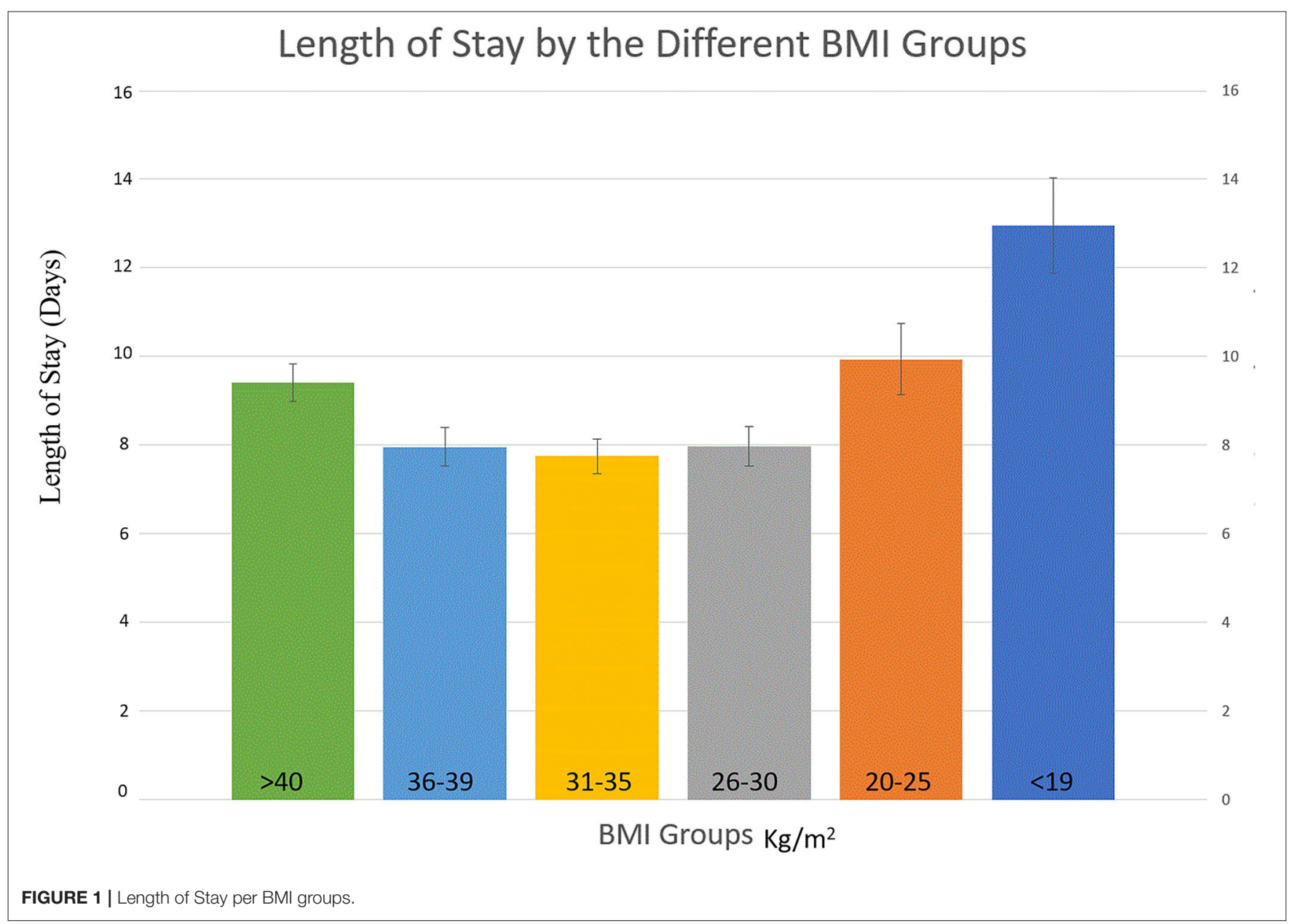

angiogram and CABG in the same index hospitalization. These patients presented more frequently with NSTEMI compared to STEMI. A very small portion (3\%) underwent CABG concomitant with valve surgery.

\section{Peri-Procedural Complications}

Peri-procedural complications in the study population are reported in Appendix Table 3. A U-shaped relation between the BMI and several periprocedural complications was noted 


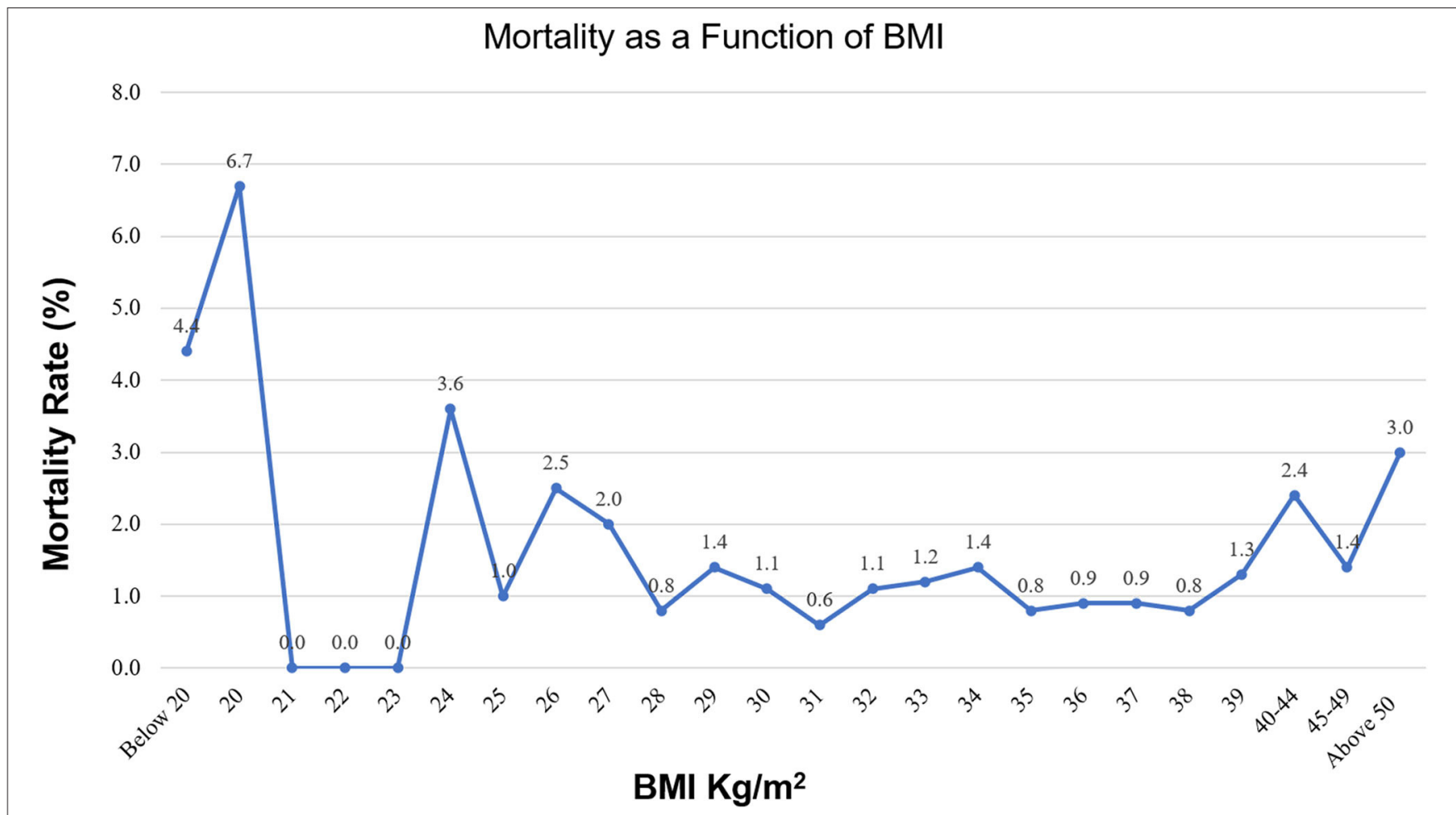

FIGURE 2 | Mortality as a function of BMI.

including in acute renal failure, infectious, pulmonary, and vascular complications. In most instances, the underweight population had the highest prevalence of complications including acute renal failure, new atrial fibrillation, cardiac complications, cardiogenic shock, need for a pacemaker, and pulmonary complications (Appendix Table 3).

\section{Length of Stay and Mortality by BMI Groups}

We observed a complex U-shaped relationship between the BMI and the study outcomes. Both the extremely obese (BMI $\geq 40$ $\left.\mathrm{kg} / \mathrm{m}^{2}\right)$ and underweight patients $\left(\mathrm{BMI} \leq 19 \mathrm{~kg} / \mathrm{m}^{2}\right)$ had a higher crude mortality and longer LOS (Figure 1). The relationship between mortality and BMI as continuous variable is presented in Figure 2. The overall rate of total mortality during the study period was $1.4 \%$ with a significantly higher mortality rate in under-weight $(4.4 \%)$ and in extremely obese $(2.2 \%)$ patient population groups $(p<0.001$; Figure 1). The mean LOS in the total cohort was $9.51 \pm 0.09$ days. Longer LOS was documented in the under-weight $(14.9 \pm 0.77$ days $)$ and in the extremely obese subgroup (10.7 \pm 0.18 days; Figure 2).

\section{Predictors of In-hospital Mortality}

In the univariate analysis, we found that baseline characteristics as older age, increasing Deyo-CCI score, chronic renal failure, atrial fibrillation/flutter, congestive heart failure, peripheral vascular disease, female sex, chronic obstructive pulmonary disease and prior sternotomy all increased the odds of in-hospital mortality $(p<0.001$; Table 3$)$.

The U-shaped relationship between BMI and outcomes were again seen in the multivariable analyses. BMI $\leq 19 \mathrm{~kg} / \mathrm{m}^{2}$ and $\mathrm{BMI} \geq 40 \mathrm{~kg} / \mathrm{m}^{2}$ remained independent predictors of inhospital mortality after adjusting for potential confounders, with a higher risk of mortality in the underweight patients compared to extremely obese patients (OR 2.64; [95\% CI: 1.48-4.71], $p<$ 0.001 vs. OR 1.71; [95\% CI: $1.07-2.72$ ], $p=0.025$, respectively; Table 4).

\section{Predictors of LOS}

Linear regression models for LOS are represented in the Appendix Tables 4, 5. BMI $\leq 19 \mathrm{~kg} / \mathrm{m}^{2}$ was found to be an independent predictor of longer hospitalization $[\mathrm{OR}=12.95$; (95\% CI: 11.88-14.03), $p<0.001]$. Other predictors for longer LOS were older age, Deyo-CCI score \pm 2 , atrial fibrillation, congestive heart failure, and chronic renal failure. Additionally, were patients who presented with acute coronary syndrome and who underwent percutaneous coronary intervention or concomitant valve surgery in the same index hospitalization (Appendix Tables 4, 5).

\section{DISCUSSION}

Utilizing data from the NIS, the largest all-payer inpatient database in the U.S., we identified a weighted total of 48,710 
TABLE 3 | Univariate analysis for predictors of in-hospital mortality, 2015-2016.

\begin{tabular}{|c|c|c|}
\hline Predictor & $\begin{array}{l}\text { Odds ratio } \\
(95 \% \mathrm{Cl})\end{array}$ & $P$-value \\
\hline $\mathrm{BMI} \mathrm{kg} / \mathrm{m}^{2}$ group & & $<0.001$ \\
\hline$\leq 19$ & $2.97(1.67-5.27)$ & $<0.001$ \\
\hline $20-25$ & 1.00 (reference) & N/A \\
\hline $26-30$ & $0.88(0.54-1.42)$ & 0.596 \\
\hline $31-35$ & $0.66(0.42-1.06)$ & 0.085 \\
\hline $36-39$ & $0.64(0.39-1.03)$ & 0.068 \\
\hline$\geq 40$ & $1.45(0.92-2.30)$ & $<0.001$ \\
\hline Age group, years & & $<0.001$ \\
\hline $18-44$ & 1.00 (reference) & $\mathrm{N} / \mathrm{A}$ \\
\hline $45-59$ & $1.70(0.89-3.23)$ & 0.106 \\
\hline $60-74$ & $2.41(1.28-4.53)$ & 0.006 \\
\hline$\geq 75$ & $5.02(2.65-9.51)$ & $<0.001$ \\
\hline Deyo-CCl & & $<0.001$ \\
\hline 0 & $0.43(0.22-0.84)$ & 0.01 \\
\hline 1 & 1.00 (reference) & N/A \\
\hline 2 or higher & $3.39(2.54-4.52)$ & $<0.001$ \\
\hline Gender & & $<0.001$ \\
\hline Male & 1.00 (reference) & N/A \\
\hline Female & $1.66(1.42-1.93)$ & $<0.001$ \\
\hline Race & & 0.42 \\
\hline Non-white & 1.00 (reference) & $\mathrm{N} / \mathrm{A}$ \\
\hline White & $0.92(0.75-1.13)$ & 0.42 \\
\hline Comorbidities & & $<0.001$ \\
\hline \multicolumn{3}{|l|}{ Atrial fibrillation/flutter } \\
\hline No & 1.00 (reference) & $\mathrm{N} / \mathrm{A}$ \\
\hline Yes & $2.08(1.79-2.42)$ & $<0.001$ \\
\hline Chronic obstructive pulmonary disease & & 0.02 \\
\hline No & 1.00 (reference) & N/A \\
\hline Yes & $1.22(1.03-1.45)$ & 0.02 \\
\hline Congestive heart failure & & $<0.001$ \\
\hline No & 1.00 (reference) & N/A \\
\hline Yes & $1.90(1.59-2.28)$ & $<0.001$ \\
\hline Diabetes mellitus & & 0.009 \\
\hline No & 1.00 (reference) & $N / A$ \\
\hline Yes & $1.22(1.05-1.42)$ & 0.009 \\
\hline Hypertension & & $<0.001$ \\
\hline No & 1.00 (reference) & N/A \\
\hline Yes & $0.42(0.36-0.49)$ & $<0.001$ \\
\hline Peripheral vascular disease & & $<0.001$ \\
\hline No & 1.00 (reference) & N/A \\
\hline Yes & $2.78(2.36-3.28)$ & $<0.001$ \\
\hline Chronic renal failure & & $<0.001$ \\
\hline No & 1.00 (reference) & N/A \\
\hline Yes & $2.54(2.18-2.97)$ & $<0.001$ \\
\hline \multicolumn{3}{|l|}{ Clinical Course } \\
\hline NSTEMI & & $<0.001$ \\
\hline No & 1.00 (reference) & N/A \\
\hline Yes & $2.09(1.79-2.43)$ & $<0.001$ \\
\hline
\end{tabular}

(Continued)
TABLE 3 | Continued

\begin{tabular}{lcc}
\hline Predictor & $\begin{array}{c}\text { Odds ratio } \\
(\mathbf{9 5 \%} \mathbf{C l})\end{array}$ & $\boldsymbol{P}$-value \\
\hline STEMI & 1.00 (reference) & $<0.001$ \\
No & $\mathrm{N} / \mathrm{A}$ \\
Yes & $3.12(2.50-3.88)$ & $<0.001$ \\
Percutaneous coronary intervention & 1.00 (reference) & $\mathrm{N} / \mathrm{A}$ \\
No & $2.58(1.87-3.57)$ & $<0.001$ \\
Yes & & 0.021 \\
Prior sternotomy & 1.00 (reference) & $\mathrm{N} / \mathrm{A}$ \\
No & $1.23(1.03-1.48)$ & 0.02 \\
Yes & 1.00 (reference) & $<0.001$ \\
Concomitant valve surgery & $\mathrm{N} / \mathrm{A}$ \\
No & $4.05(3.14-5.21)$ & $<0.001$ \\
Yes & & $<0.001$ \\
VFNT & 1.00 (reference) & $\mathrm{N} / \mathrm{A}$ \\
No & $9.17(7.79-10.81)$ & $<0.001$ \\
Yes &
\end{tabular}

BMI, Body Mass Index; Deyo-CCl, Deyo-Charlson Comorbidity Index; NSTEMI, NonST Segment Elevation Myocardial Infraction; STEMI, ST segment Myocardial Infraction; VFNT, Ventricular Flutter/Ventricular Fibrillation.

patients to investigate the relationship between $\mathrm{BMI}$ and inhospital outcomes among patients undergoing CABG. To our knowledge, this is the single largest study analyzing the relationship between BMI and CABG in-hospital outcomes. This nationwide data analysis revealed a U-shaped relationship between the BMI and in-hospital mortality during hospitalization for CABG in the U.S. during the study period. BMI $\leq 19 \mathrm{~kg} / \mathrm{m}^{2}$ and $\mathrm{BMI} \geq 40 \mathrm{~kg} / \mathrm{m}^{2}$ were both independent predictors of higher mortality and longer length of stay in patients post CABG in the U.S. during the study period.

Several studies investigated the effect of different BMI arrays on short- and long-term mortality with contradictory results. Some studies suggested that obesity was an independent negative predictor of morbidity and mortality (5-8) while other showed more favorable outcomes after cardiac surgery in obese patients (9-13). This could partially be explained by the poor association between obese and non-obese groups in comparing morbidity and mortality; many of the studies lacked the "under-weight" and "severe obesity" patient populations in their statistical comparisons of different BMI groups.

Obesity is a rising global epidemic affecting $10-20 \%$ of the world's adult population (24), and is further known to complicate anesthesia (27) and surgery with fatal and non-fatal events. Prior studies showed higher rates of surgical site infections in obese patients, venous thromboembolism, more significant blood loss and the need of blood transfusions, as well as longer surgical times $(28,29)$. Other studies showed increased rates of urine and respiratory infections and post-surgery myocardial infarction events in obese patients (29). Specifically, after CABG surgery, obesity is a strong risk factor for deep sternal wound infections and as such serves an indicator of higher morbidity rates (30). 
TABLE 4 | Multivariable analysis for predictors of in-hospital mortality, 2015-2016.

\begin{tabular}{|c|c|c|}
\hline Predictor & $\begin{array}{l}\text { Odds ratio } \\
(95 \% \mathrm{Cl})\end{array}$ & $P$-value \\
\hline 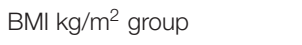 & & $<0.001$ \\
\hline $20-25$ & 1.00 (reference) & $\mathrm{N} / \mathrm{A}$ \\
\hline$\leq 19$ & $2.64(1.48-4.71)$ & $<0.001$ \\
\hline $26-30$ & $0.86(0.52-1.40)$ & 0.541 \\
\hline $31-35$ & $0.70(0.43-1.12)$ & 0.140 \\
\hline $36-39$ & $0.76(0.47-1.25)$ & 0.288 \\
\hline$\geq 40$ & $1.71(1.07-2.73)$ & 0.025 \\
\hline Age group, years & & $<0.001$ \\
\hline $18-44$ years & 1.00 (reference) & $\mathrm{N} / \mathrm{A}$ \\
\hline $45-59$ years & $1.68(0.88-3.21)$ & 0.116 \\
\hline $60-74$ years & $2.32(1.23-4.38)$ & 0.009 \\
\hline 75 years or older & $4.53(2.37-8.66)$ & $<0.001$ \\
\hline Deyo-CCl & & $<0.001$ \\
\hline 1 & 1.00 (reference) & $\mathrm{N} / \mathrm{A}$ \\
\hline 2 or higher & $3.46(2.50-4.77)$ & $<0.001$ \\
\hline Gender & & $<0.001$ \\
\hline Male & 1.00 (reference) & $\mathrm{N} / \mathrm{A}$ \\
\hline Female & $1.42(1.21-1.68)$ & $<0.001$ \\
\hline Race & & 0.470 \\
\hline Non-white & 1.00 (reference) & $\mathrm{N} / \mathrm{A}$ \\
\hline White & $0.93(0.75-1.14)$ & 0.470 \\
\hline $\begin{array}{l}\text { Comorbidities } \\
\text { Atrial fibrillation/flutter }\end{array}$ & Atrial fibrillation/flutter & $<0.001$ \\
\hline No & 1.00 (reference) & $\mathrm{N} / \mathrm{A}$ \\
\hline Yes & $1.80(1.53-2.12)$ & $<0.001$ \\
\hline COPD & & 0.208 \\
\hline No & 1.00 (reference) & $\mathrm{N} / \mathrm{A}$ \\
\hline Yes & $0.89(0.74-1.07)$ & 0.208 \\
\hline Congestive heart failure & & 0.002 \\
\hline No & 1.00 (reference) & $\mathrm{N} / \mathrm{A}$ \\
\hline Yes & $1.36(1.13-1.65)$ & 0.002 \\
\hline Diabetes mellitus & & 0.718 \\
\hline No & 1.00 (reference) & $\mathrm{N} / \mathrm{A}$ \\
\hline Yes & $0.97(0.82-1.14)$ & 0.718 \\
\hline Hypertension & & $<0.001$ \\
\hline No & 1.00 (reference) & N/A \\
\hline Yes & $0.56(0.47-0.66)$ & $<0.001$ \\
\hline Peripheral vascular disease & & $<0.001$ \\
\hline No & 1.00 (reference) & $\mathrm{N} / \mathrm{A}$ \\
\hline Yes & $2.25(1.89-2.68)$ & $<0.001$ \\
\hline Chronic renal failure & & $<0.001$ \\
\hline No & 1.00 (reference) & $\mathrm{N} / \mathrm{A}$ \\
\hline Yes & $1.72(1.45-2.03)$ & $<0.001$ \\
\hline Clinical course & & $<0.001$ \\
\hline NSTEMI & & \\
\hline No & 1.00 (reference) & $\mathrm{N} / \mathrm{A}$ \\
\hline Yes & $1.62(1.38-1.90)$ & $<0.001$ \\
\hline STEMI & & $<0.001$ \\
\hline No & 1.00 (reference) & $\mathrm{N} / \mathrm{A}$ \\
\hline Yes & $2.99(2.36-3.77)$ & $<0.001$ \\
\hline
\end{tabular}

(Continued)
TABLE $4 \mid$ Continued

\begin{tabular}{lcc}
\hline Predictor & $\begin{array}{c}\text { Odds ratio } \\
\mathbf{( 9 5 \% ~ C l )}\end{array}$ & P-value \\
\hline Percutaneous coronary intervention & 1.00 (reference) & $\mathrm{N} / \mathrm{A}$ \\
$\quad$ No & $2.22(1.56-3.16)$ & $<0.001$ \\
$\quad$ Yes & 1.00 (reference) & 0.224 \\
Prior sternotomy & $\mathrm{N} / \mathrm{A}$ \\
No & $1.13(0.93-1.36)$ & 0.224 \\
Yes & & $<0.001$ \\
Concomitant valve surgery & $1.00($ reference) & $\mathrm{N} / \mathrm{A}$ \\
No & $3.12(2.36-4.12)$ & $<0.001$ \\
Yes & & $<0.001$ \\
VFNT & $1.00($ reference) & $\mathrm{N} / \mathrm{A}$ \\
No & $8.02(6.72-9.57)$ & $<0.001$ \\
Yes & &
\end{tabular}

BMI, Body Mass Index; Deyo-CCl, Deyo-Charlson Comorbidity Index; NSTEMI, NonST Segment Elevation Myocardial Infraction; STEMI, ST segment Myocardial Infraction; VFNT, Ventricular Flutter/Ventricular Fibrillation.

Currently, there is a lack of publications studying cachexia and survival rates in post CABG patients.

On the contrary to the abovementioned studies, others showed that higher weight individuals conferred better survival after surgery. One possible explanation is that high BMI may be beneficial by providing nutritional and caloric reserves in severely and critically ill patients. This is supported by previous studies in additional chronic, debilitating cardiovascular and non-cardiovascular conditions, in which both under-weight and normal weight BMI was associated with increased mortality rates, compared to higher-BMI groups (3, 31-33). Further studies supported that severe cardiovascular disease, such as heart failure, results in tissue hypoperfusion and cardiac cachexia. The hypothesis is that this state resulting from a heightened metabolic or increased catabolic state is associated with worse prognosis $(34,35)$. On the other hand, elevated BMI might indicate a better metabolic reserve and tolerance to metabolic stress and consequently to a better prognosis (36).

Our study results improve the available literature on the negative association of extremely obese BMI subgroups and early mortality following CABG. Of note, the Society of Thoracic Surgeons (STS) uses statistical models to create risk-adjusted performance metrics for Adult Cardiac Surgery Database (ACSD) participants. BSA and BMI were both independently associated with mortality, and O'Brien et al. (26) found that inclusion of both variables was needed to capture variation in the residuals. In line with our findings, they also demonstrated a $U$ shape relationship between BMI and mortality (26), reflected in the STS score. In contrast, BMI has not been directly included in the current European (EuroSCORE II) score (37). We believe that this important correlation between BMI and mortality should be reflected in all surgical risk scores.

Contrary to many previous clinical studies, we included the "real world" BMI spectrum including the underweight, normal weight and extremely obese patients for a complete 
representation. Our results showed that underweight patients undergoing CABG $\left(B M I \leq 19 \mathrm{~kg} / \mathrm{m}^{2}\right)$ have the highest risk of mortality compared to the other BMI groups.

This study population represents the entire, nationwide population of patients who underwent CABG in the U.S between October 2015 and December 2016, hence eliminating the "selection bias" in some of the prior studies regarding CABG patients.

The current study should be interpreted in the contexts of several limitations. First, the NIS database is a retrospective administrative database that contains discharge-level records and as such is susceptible to coding errors. The NIS database does not include detailed information about the patients' clinical characteristics, medication, blood tests such as level of cholesterol and markers of inflammation, all of which have been independently linked with adverse cardiovascular events, therefore we cannot rule out residual confounding of the associations we observed. Unfortunately, no data about the number/type of diseased vessels (SYNTAX score etc.), the number of coronary bypass and the techniques preferred (venous vs. arteriosus graft, off-pump BH, etc.) have been included in our study, despite of increasing interest. In addition, the lack of patient identifiers in the NIS precluded us from using other outcome variables and mortality measures such as at 30-days, we could only capture events that occurred in the same index hospitalization. These limitations are counterbalanced by the real world, nationwide nature of the data, as well as mitigation of reporting bias introduced by selective publication of results from specialized centers.

In conclusion, a U-shaped relationship between BMI and mortality was documented in patients hospitalized for CABG in the recent years. Accordingly, BMI should be addressed and considered as part of the risk assessment for in-hospital mortality in patients who are planned for CABG.

\section{REFERENCES}

1. Khan SS, Ning H, Wilkins JT, Allen N, Carnethon M, Berry JD, et al. Association of body mass index with lifetime risk of cardiovascular disease and compression of morbidity. JAMA Cardiol. (2018) 3:2807. doi: 10.1001/jamacardio.2018.0022

2. Available online at: http://www.euro.who.int/en/health-topics/diseaseprevention/nutrition/a-healthy-lifestyle/body-mass-index-bmi (accessed July 7, 2020).

3. Lavie CJ, Milani RV, Ventura HO. Obesity and cardiovascular disease: risk factor, paradox, and impact of weight loss. J Am Coll Cardiol. (2009) 53:192532. doi: 10.1016/j.jacc.2008.12.068

4. Muller MJ, Braun W, Enderle J, Bosy-Westphal A. Beyond BMI: conceptual issues related to overweight and obese patients. Obes Facts. (2016) 9:193205. doi: $10.1159 / 000445380$

5. Sun Y, Jiang D, Zhang B, Yu H, Gao Y, Li Y, Qi G. Impact of obesity on the outcome of Chinese patients with ST-segment myocardial infarction undergoing urgent percutaneous coronary intervention. Acta Cardiol. (2012) 67:541-8. doi: 10.1080/AC.67.5.2174128

6. Montazerghaem H, Safaie N, Samiei Nezhad V. Body mass index or serum albumin levels: which is further prognostic following cardiac surgery? J Cardiovasc Thorac Res. (2014) 6:123-6. doi: 10.5681/jcvtr.2014.026

7. Zittermann A, Becker T, Gummert JF, Borgermann J. Body mass index, cardiac surgery and clinical outcome. A single-center experience with 9125 patients.

\section{DATA AVAILABILITY STATEMENT}

The datasets presented in this study can be found in online repositories. The names of the repository/repositories and accession number(s) can be found in the article/Supplementary Material.

\section{ETHICS STATEMENT}

Ethical review and approval was not required for the study on human participants in accordance with the local legislation and institutional requirements. Written informed consent for participation was not required for this study in accordance with the national legislation and the institutional requirements.

\section{AUTHOR CONTRIBUTIONS}

All authors listed have made a substantial, direct, and intellectual contribution to the work, and approved it for publication.

\section{ACKNOWLEDGMENTS}

The GE-G affirms that she has listed everyone who contributed significantly to the work, had access to all the study data, takes responsibility for the accuracy of the analysis, and had authority over the manuscript preparation and the decision to submit the manuscript for publication, and confirms that all authors read and approved the manuscript.

\section{SUPPLEMENTARY MATERIAL}

The Supplementary Material for this article can be found online at: https://www.frontiersin.org/articles/10.3389/fcvm. 2021.754934/full\#supplementary-material

Nutr Metab Cardiovasc Dis. (2014) 24:168-75. doi: 10.1016/j.numecd.2013. 06.013

8. Caliskan E, Gusewell S, Seifert B, Theusinger OM, Starck CT, Pavicevic J, et al. Does body mass index impact the early outcome of surgical revascularization? A comparison between off-pump and on-pump coronary artery bypass grafting. Interact Cardiovasc Thorac Surg. (2014) 19:749-55. doi: 10.1093/icvts/ ivu246

9. Reeves BC, Ascione R, Chamberlain MH, Angelini GD. Effect of body mass index on early outcomes in patients undergoing coronary artery bypass surgery. J Am Coll Cardiol. (2003) 42:668-76. doi: 10.1016/S0735-1097(03) 00777-0

10. Wiedemann D, Schachner T, Bonaros N, Weidinger F, Kolbitsch C, Friedrich $\mathrm{G}$, et al. Does obesity affect operative times and perioperative outcome of patients undergoing totally endoscopic coronary artery bypass surgery? Interact Cardiovasc Thorac Surg. (2009) 9:214-7. doi: 10.1510/icvts.2009.2 03059

11. Le-Bert G, Santana O, Pineda AM, Zamora C, Lamas GA, Lamelas J. The obesity paradox in elderly obese patients undergoing coronary artery bypass surgery. Interact Cardiovasc Thorac Surg. (2011) 13:1247. doi: $10.1510 /$ icvts.2010.256677

12. Wang TK, Ramanathan T, Stewart R, Gamble G, White H. Lack of relationship between obesity and mortality or morbidity after coronary artery bypass grafting. NZ Med J. (2013) 126:56-65. 
13. Zhang Y, Zheng Q, Dai X, Xu X, Ma L. Overweight is associated with better one-year survival in elderly patients after cardiac surgery: a retrospective analysis of the MIMIC-III database. J Thorac Dis. (2021) 13:56274. doi: 10.21037/jtd-20-2824

14. Wang $M$, Chen $M$, Ao $H$, Chen S, Wang Z. The effects of different BMI on blood loss and transfusions in Chinese patients undergoing coronary artery bypass grafting. Ann Thorac Cardiovasc Surg. (2017) 23:8390. doi: 10.5761/atcs.oa.16-00219

15. Brunet A, N'Guyen Y, Lefebvre A, Poncet A, Robbins A, Bajolet O, et al. Obesity and preoperative anaemia as independent risk factors for sternal wound infection after coronary artery bypass graft surgery with pedicled (nonskeletonized) internal mammary arteries: the role of thoracic wall ischemia? Vasc Health Risk Manag. (2020) 16:553-9. doi: 10.2147/VHRM.S264415

16. Atik FA, Pegado HM, de Brito LMR, Macedo MT, Franca EP Jr, Dias AKA, et al. Does the anthropometric profile influence infection morbidity after coronary artery bypass grafting? J Card Surg. (2021) 36:1194200. doi: 10.1111/jocs.15334

17. Buschmann K, Wrobel J, Chaban R, Rosch R, Ghazy A, Hanf A, et al. Body mass index (BMI) and its influence on the cardiovascular and operative risk profile in coronary artery bypass grafting patients: impact of inflammation and leptin. Oxid Med Cell Longev. (2020) 2020:5724024. doi: 10.1155/2020/5724024

18. Healthcare Cost Utilization Project (HCUP). Agency for Healthcare Research Quality $R$ (2000-2011). Available online at: www.hcup-us.ahrq.gov/nisoverview.jsp (accessed July 7, 2020).

19. HCUP National Inpatient Sample (NIS). Healthcare Cost Utilization Project (HCUP). Agency for Healthcare Research Quality R, MD (2012-2013). Available online at: www.hcup-us.ahrq.gov/nisoverview.jsp (accessed July 07, 2020).

20. Steiner C, Elixhauser A, Schnaier J. The healthcare cost and utilization project: an overview. Eff Clin Pract. (2002) 5:143-51.

21. Deyo RA, Cherkin DC, Ciol MA. Adapting a clinical comorbidity index for use with ICD-9-CM administrative databases. J Clin Epidemiol. (1992) 45:613-9. doi: 10.1016/0895-4356(92)90133-8

22. Chu YT, Ng YY, Wu SC. Comparison of different comorbidity measures for use with administrative data in predicting short- and long-term mortality. BMC Health Serv Res. (2010) 10:140. doi: 10.1186/1472-6963-10-140

23. Radovanovic D, Seifert B, Urban P, Eberli FR, Rickli H, Bertel O, et al. Validity of Charlson Comorbidity Index in patients hospitalised with acute coronary syndrome. Insights from the nationwide AMIS Plus registry 2002-2012. Heart. (2014) 100:288-94. doi: 10.1136/heartjnl-2013-304588

24. Kappetein AP, Head SJ, Genereux P. Updated standardized endpoint definitions for transcatheter aortic valve implantation: the Valve Academic Research Consortium-2 consensus document (VARC-2). Eur J Cardiothorac Surg. (2012) 42:45-60. doi: 10.1093/ejcts/ezs533

25. Hosseini SM, Moazzami K, Rozen G, Vaid J, Saleh A, Heist KE, et al. Utilization and in-hospital complications of cardiac resynchronization therapy: trends in the United States from 2003 to 2013. Eur Heart J. (2017) 38:2122-28. doi: 10.1093/eurheartj/ehx100

26. O'Brien SM, Liqi F, He X, Xian Y, Jacobs JP, Badhwar V, et al. The STS 2018 adult cardiac surgery risk models: part 2 - statistical methods \& results. Ann Thorac Surg. (2018) 105:1419-28. doi: 10.1016/j.athoracsur.2018.03.003

27. Lotia S, Bellamy MC. Anaesthesia and morbid obesity. Continuing education in anaesthesia. Crit Care Pain. (2008) 8:151-6. doi: 10.1093/bjaceaccp/mkn030
28. Jiang J, Teng Y, Fan Z, Khan S, Xia Y. Does obesity affect the surgical outcome and complication rates of spinal surgery? A metaanalysis. Clin Orthop Relat Res. (2014) 472:968-75. doi: 10.1007/s11999-0133346-3

29. Bamgbade OA, Rutter TW, Nafiu OO, Dorje P. Postoperative complications in obese and nonobese patients. World J Surg. (2007) 31:556-60; discussion 561. doi: 10.1007/s00268-006-0305-0

30. Hollenbeak CS, Murphy DM, Koenig S, Woodward RS, Dunagan WC, Fraser VJ. The clinical and economic impact of deep chest surgical site infections following coronary artery bypass graft surgery. Chest. (2000) 118:397-402. doi: 10.1378/chest.118.2.397

31. Oliveros H, Villamor E. Obesity and mortality in critically ill adults: a systematic review and meta-analysis. Obesity (Silver Spring). (2008) 16:51521. doi: 10.1038/oby.2007.102

32. Kalantar-Zadeh K, Horwich TB, Oreopoulos A, Kovesdy CP, Younessi $\mathrm{H}$, Anker SD, et al. Risk factor paradox in wasting diseases. Curr Opin Clin Nutr Metab Care. (2007) 10:433-42. doi: 10.1097/MCO.0b013e3281a 30594

33. Habbu A, Lakkis NM, Dokainish H. The obesity paradox: fact or fiction? Am J Cardiol. (2006) 98:944-8. doi: 10.1016/j.amjcard.2006. 04.039

34. Kenchaiah S, Pocock SJ, Wang D, Finn PV, Zornoff LAM, Skali H, et al. Body mass index and prognosis in patients with chronic heart failure insights from the candesartan in heart failure: assessment of reduction in mortality and morbidity (CHARM) program. Circulation. (2007) 116:62736. doi: 10.1161/CIRCULATIONAHA.106.679779

35. Berry C, Clark AL. Catabolism in chronic heart failure. Eur Heart J. (2000) 21:521-32. doi: 10.1053/euhj.1999.1882

36. Coats A, Anker SD, Roecker EB, Schultz MK, Staiger C, Amann-Zalan I, et al. Prevention and reversal of cardiac cachexia in patients with severe heart failure by carvedilol: results of the COPERNICUS study. Circulation. (2001) 10:4II-437.

37. EuroSCORE Models. Available online at: http://www.euroscore.org/calcold. html (accessed July 7, 2020).

Conflict of Interest: The authors declare that the research was conducted in the absence of any commercial or financial relationships that could be construed as a potential conflict of interest.

Publisher's Note: All claims expressed in this article are solely those of the authors and do not necessarily represent those of their affiliated organizations, or those of the publisher, the editors and the reviewers. Any product that may be evaluated in this article, or claim that may be made by its manufacturer, is not guaranteed or endorsed by the publisher.

Copyright (C) 2021 Elbaz-Greener, Rozen, Carasso, Kusniec, Yarkoni, Marai, Strauss, Wijeysundera, Smart, Erez, Alcalai, Planer and Amir. This is an open-access article distributed under the terms of the Creative Commons Attribution License (CC BY). The use, distribution or reproduction in other forums is permitted, provided the original author(s) and the copyright owner(s) are credited and that the original publication in this journal is cited, in accordance with accepted academic practice. No use, distribution or reproduction is permitted which does not comply with these terms. 